\title{
Bionic organization as a stage of production enterprise development in a digital transformation process
}

\author{
Vitalii Cherepanov $^{l *}$, Evgeny Popov ${ }^{l}$, Victoria Simonova ${ }^{l}$ \\ ${ }^{1}$ Ural Institute of Management, Branch of the RANEPA, 8 Marta str. 66, 620144 Yekaterinburg, \\ Russian Federation
}

\begin{abstract}
This article embraces a concept of bionic organization as a form of production enterprise which main attribute is an integration of digital technologies in the management processes and the production lines from the product idea to its delivery to a consumer. Digital technologies reinforce human competencies and abilities of analogous machines, playing a role of independent component of executive and production system. At the same time, digital technologies become full-fledged members of the organization, enriching it with bionic treats.

An idea of full human substation in production management with digital technologies is far from being practicable, but a tendency towards this change is quite clear. The main purpose of this this article is to discover main features of bionic organization as an intermediate evolution stage on the way of full human substitution with machines and digital technologies. Additionally, the article focuses on the interconnections between bionic organization, digital transformation, digital maturity and management system. This analysis was made for a production enterprise set upon a way to deep digital transformation.
\end{abstract}

\section{Introduction}

Nowadays, the modern management process is focused not only on the staff management, but also on its reinforcement with technological solutions and on inclusion of machines and artificial intelligence as independent agents into the production process and executive system of production enterprise.

The emergence of new communication tools such as messengers, videoconferencing services, group interaction tools and chatbots makes modern interactions in organizations instant, actually uninterrupted and deprived of hierarchical constraints. This new communication pattern demands changes in management. Furthermore, this form of communications is possible not only between humans, but also between humans and machines and even between systems and machines.

On the way towards full human substitution with machines and digital technologies in production there are a lot things to be done and determined from the management methods, legislation and competency development point of view. But it is already clear that full-

\footnotetext{
* Corresponding author: v.cherepanov@outlook.com
} 
autonomous production enterprises will appear sooner or later. These production peers will not be organizations as we used to reckon those ones, but they will demand specific approach in management, strategy development and engineering role of human. Finally, market will always demand compliance of proposed product to human necessities, those constantly change. As it is well-known that only "alive" systems are able to adapt to the environmental conditions and circumstances, changing its inner organization or structure [1]. However, this adoption is a goal of a modern organization on the way of Industry 4.0 development, as it suggested by Acatech [2]. The main purpose of transition towards Industry 4.0, contrary to many opinions, is not fully blown automation of production processes, but attainment of agility, readiness to changes and mobility to get necessary competitive advantages in a struggle for consumers.

Strengthening of normal biologic treats or performance with electronic or electromechanical devices is bionic [3]. Is it possible to apply this concept to an organization? The main goal of this article is to discover main features of bionic organization as an intermediate stage of organization evolution and to find a place of this stage in entire digital transformation process.

On this way we took into account that concept of "bionics" was introduced by Jack E. Steele, as a merger of "biology" and "electronics". Nowadays, this direction of science is focused on biologic methods and systems features application towards engineering tasks and modern technologies [4].

As we discovered earlier, a number of researches have already made some steps towards concept of bionic organization. This concept is actively developing by Boston Consulting Group in a cycle of articles and conferences.

This article contains a research of main features of bionic organizations and authors vision of a role of bionic organization as a stage of organizational evolutions in digital transformation, pointed to full-autonomous production enterprise as a finite form of this transformation. A relevance of the research is proved by increase interest towards artificial intelligence, increase of production efficiency and decrease of human physical interconnections in order to reduce the rate of spread of viral infections, as a main output of COVID-19 pandemic, connected with human labor $[5,6]$.

\section{Materials and methods}

There were two methods used in this research: i) discovering of scientific, popular scientific and information publications connected with a topic of the research; and ii) modelling of changes the essence of main features of production enterprise when its key agents of managements systems and production are replaces with machines and digital technologies.

In this research, the authors lean on their own outputs on digital technologies. They consider digital technologies as technologies those support actions and interactions with reduction of cognitive limits of humans, overcoming time and space, equally between humans, devices, machines and systems as equal agents with certain role defined by creator of digital technology or platform.

In addition, the authors draw from their own typology of digital maturity levels of an organization, those include the following stages of digital transformation (see Table 1 that follows).

In analysis process, we discovered a plethora of publications on the topic of the research and on related topics. Google, analytical system Teqviser, online library Wiley, Elsevier ScienceDirect, Springer Open, Informs, arXiv of Cornell University, insights of McKinsey, Boston Consulting Group, PriceWaterhouse Coopers and Bain\&Co. were used to assess an to classify them [7]. 
Table 1. Levels of digital maturity (for production enterprise)

\begin{tabular}{|c|c|l|}
\hline № & $\begin{array}{c}\text { Level of digital maturity (towards } \\
\text { digital technologies usage) }\end{array}$ & \multicolumn{1}{c|}{ The essence } \\
\hline 1. & Lack of & $\begin{array}{l}\text { Fully manual labor or usage of analogous } \\
\text { machines }\end{array}$ \\
\hline 2. & Existence & $\begin{array}{l}\text { Usage of digital technologies in social life in } \\
\text { communications, but not in production } \\
\text { process of management system }\end{array}$ \\
\hline 3. & Application & $\begin{array}{l}\text { Usage of digital technologies to particular } \\
\text { tasks and problems }\end{array}$ \\
\hline 4. & Using & $\begin{array}{l}\text { Composition of processes and interactions } \\
\text { based on digital technologies }\end{array}$ \\
\hline 5. & Aubstitution & $\begin{array}{l}\text { Gradual substitution of management } \\
\text { functions of humans to digital technologies }\end{array}$ \\
\hline 6. & & $\begin{array}{l}\text { Transition towards a stage, when digital } \\
\text { technologies create new processes of } \\
\text { interactions, means of labor or technologies } \\
\text { and manage a production process. Enterprise } \\
\text { operates without humans }\end{array}$ \\
\hline
\end{tabular}

Note: Authors' typology of digital maturity levels is getting ready to be publish in an individual article in Russian

The main search criteria were the following (see Table 2).

Table 2. Keywords used in literature review

\begin{tabular}{|l|l|}
\hline \multicolumn{1}{|c|}{ Direction of the "bionic organization" } & \multicolumn{1}{c|}{ Related topics } \\
\hline $\begin{array}{l}\text { Bionic company, bionic organization, bionic } \\
\text { plant, autonomous production, bionic } \\
\text { management, bionic (in economics and } \\
\text { management) }\end{array}$ & $\begin{array}{l}\text { Digital transformation, digitalization, digital } \\
\text { technologies, artificial intelligence, patterns of } \\
\text { organizational structures, stages of } \\
\text { organizational development }\end{array}$ \\
\hline
\end{tabular}

When modelling the essence of changes of production enterprises in digital transformation process, there were distinguished production machines, information systems, means and methods of interactions, technologies, processes and roles as components of management and production system. The conducted research was also based on published researches on bionic organizations and related fields.

\section{Prevailing views on bionic organizations}

One of the first mentions of bionic organization was published in Clay Carr's cycle of researches, published from 1989 to 1990. In the first research in 1989, Carr distinguished three features of bionic organization [8]:

1. Key agents of activities include not only humans, but computer systems.

2. Any agent of activity or employee has an access towards massive storage of an information and knowledge of organization. 
3. All organization members including computer systems can interact with each other using common methods.

Actually, Carr described modern organization with digital assistants, chatbots, artificial intelligence and messengers for communications. Considering such an organization as a bionic, he emphasized that computer systems become full-fledged members of processes. In the early 2000s there were mentions [9] of bionic organization, using technologies in its processes. After these researches there were no detailed mentions of bionic organization in scientific researches and publications on economics, managements and related fields. Further development of bionic organization concept took place in 2018-2019 in articles of PriceWaterhouse Coopers [10] and Boston Consulting Group [11]. The main point of those publications is that technological solutions and especially digital technologies such as artificial intelligence and big data, allow to enhance human competencies and broaden capabilities of organization [12].

Other modern researches note [13], that technologies and approaches to knowledge management could be developed if those points are supported by big data and artificial intelligence. This confirms Clay Carrs's withdrawals about availability of knowledge in bionic organization as its main feature, because this enhanced knowledge can widen human competencies.

Apart from working with data, in modern organizations there are a lot of digital assistants [14] which play humans roles in matters of support, requests handling and so on. But this role should be regulated and defined, because digital assistant cannot just substitute human. The matter of responsibility for the function delegated to a digital assistant becomes critical, because digital technologies are not able to be responsive, but humans do not already perform a function.

A similar output researches offer [15] in a matter of artificial intelligence and its integration in modern management systems. This integration should be regulated, in order to avoid humans fears and deep concerns those could arise because some parts of power and control go to machines and digital technologies.

At the same time, digital technologies development move workplaces away from productions facilities and creates significant trend towards coworking forms of interactions and workplaces structuring [16]. This change also demands correct interaction rules and approaches to work with production objects.

Social interaction is still in high demand, but it lost a necessity of direct physical contact in knowledge transfer processes, especially because of the COVID-19 pandemic. Social networks play the increasingly important role. Those networks become something like courts and platforms in international collaboration of corporations [17] which play a role of agents in social networks.

Finally, modern business tends to deeper integration of software in its processes those begins to drive business [18]. Dependence of the management and productions systems on software and information and communication technologies is different and defined by industry, character of activity and ability to digitize products and services, but a common tendency towards software key role is obvious.

Modern organizations have a lot of described features, but is it correct to consider those organizations bionic? In what points are bionic organization connected with digital transformation and is it correct to view both concepts mutually in context of digital technologies? This research allows us to make the following outputs in return to these questions. 


\section{Vision of bionic organization as a stage of organization's evolution in digital transformation}

First of all, it should be mentioned that the published researches on the topic in question does not answer the questions about decision-making process for humans and digital agents in modern business. Who does define these decisions and make a structure and routines of organizational processes?

Actually, if an organization uses digital technologies to make its production more efficient, but decisions are made by humans, that means that digital technologies do not influence on the organization. It also means that the organization is still the same in its essence and DNA and has no bionic features. This kind of organizations, where all the main decisions and competencies are fixed to humans, should be considered as "biological".

The finite goal of a digital transformation process of production enterprise is a level of digital maturity, where invested funds and efforts bring an expected effect and organization is still competitive, profitable and ready to produce products and services demanded by target consumers. This process is usually connected with the goal to attain the highest level of digital maturity in every process in this organization.

The finite stage of digital transformations is a full-autonomous organization, that works without a role, but with a task of a human. This organizational stage has main specific: organizations stop being an organization and becomes a technical system. This stage is specific, because organization loses its main features and components: functions, staff, competencies, relationships, human, behavioral and social capital and in some extent even knowledge. Finally, it can be concluded that at this stage organization becomes autonomous (technical) system, but not an organization. This system is under controls of a human or a group of humans, who compose a kind of a new group with specific type, but they are not organization in itself, because all of its components were substituted by the digital technologies and machines. It is evident that because of its complexity this new technical autonomous system could not be run by this group completely. This system demands quite a bunch of deep competencies and knowledge to operate and take care of it. This system will demand skills of external engineering companies, architects and experts in system development and management. The group of people running the system will be focused only on its management and definitions of tasks for it.

Digital transformation up to the level of autonomy is impossible without going through certain stages of organizational evolutions from digital transformation point of view. We reckon that one of these stages is a stage of bionic organization. Actually, this is a stage of transforming a biological organization, where decisions are made by humans, to an autonomous (technical) system, where decisions are made by digital technologies and humans become a kind of owner or even specifier.

\begin{tabular}{|c|c|c|}
\hline \multicolumn{3}{|c|}{ Levels of digital maturity } \\
\hline $\begin{array}{c}\text { Biological } \\
\text { organization }\end{array}$ & $\begin{array}{c}\text { Bionic } \\
\text { organization }\end{array}$ & $\begin{array}{l}\text { Autonomous } \\
\text { (technical) } \\
\text { system }\end{array}$ \\
\hline \multicolumn{3}{|c|}{ Levels of digital maturity } \\
\hline $\begin{array}{c}\text { Lack of } \\
\text { Existence } \\
\text { Application }\end{array}$ & $\begin{array}{c}\text { Using } \\
\text { Substitution }\end{array}$ & Autonomy \\
\hline
\end{tabular}

Fig. 1. Stages of organizational evolution in digital transformation process 
Considering the approach of defining an organizational type based on decisions owner, it should be remarked that an organization could be depicted as a bionic if only managerial and production solutions are made by digital technologies (e.g. artificial intelligence (AI)) at least partly. Thereby, the main stages of organizational evolution include the following (see Figure 1).

Social dynamics and struggle for power and control in a bionic organization also get changes on this stage. A lot of decisions move from humans to digital technology components and organization faces a new issue, who will be responsible for these decisions.

A human is not limited in a space of one's decisions. This space is limited with abilities, competencies, moral convictions or values. Every machine or technology has a limited space of decisions defined by its designer, creator or specifier. This machine or technology can also be limited by a complex of supported algorithms in its decision space. This means that a human defined a space of decisions is responsible for certain decisions made by a machine or digital technology that is run with such a space of decisions.

Machine or digital technology is stronger than a human in tasks with certain or in general finite space of decision variants or actions. However modern machines produce art objects with high value [19], decision space of these machines is finally limited by developer's imagination and competencies. At the same time human imagination is almost infinite, except intrinsic borders those a human made for oneself personally.

Discovering an engagement of digital technologies in decision making process in bionic organization, we should remark that managerial tasks on these process steps comes down to defining a space of decisions with certain alternatives or limits with detailed parameters of such decisions [20]. For example, it is necessary to define temperature limitations to change, amounts to be paid automatically and so on.

Further digital technologies development, as it was mentioned before, will lead to complete human exclusion from the production process, but a key aspect of that is a disappearance of relationships in organization. When relationships disappear from the executive system, executive system moves to tasks set-up and constraining space of decisions. This key change will create autonomous (technical) system those main features of organization fade. This system also loses a main feature of biological organization - an ability to change and adopt to environment conditions and, finally, to market conditions. At this stage of organizational evolution connections between "human" and "machine" become definite: a human defines a space of decisions for digital technologies and is responsible for system's adoption to the environment and digital solutions support all system's processes in defined limits and provide it with demanded level of agility and desired efficiency.

This content of digital transformation concept makes a clear evidence of a further relevance of human in production facilities and especially in social frameworks. Organization needs an adoption to the environment it works in and to the market it is aimed at even at the stage of autonomous (technical) system. This adoption is an alien feature of technical systems, hence human have to play a role of an architect of the adoption to market and environment for this system in future, as a biological organism.

\section{Conclusions}

Overall, the main results of the research can be summarized as follows: First of all, it becomes apparent that bionic organization is an intermediate stage of organizational evolution in a digital transformation process between biological organization towards autonomous (technical) system.

Second, an organization could be considered as bionic if it has transformed to a digital maturity level "using" or "substitution" from the digital technologies point of view. These 
levels are among ones defined by authors of the article in their own concept of digital maturity.

Third, functions transfer from a human to digital technologies and solutions, including artificial intelligence, doesn't redeem managers from a responsibility for decisions made by these technological solutions. On the contrary, making a way from bionic organization towards autonomous system, create new managerial task to define a space of decisions and limits for digital technologies in production and executive system.

Fourth, a concept of bionic organization allows defining stages of organizational evolution from the digital transformation point of view. This path starts with biological organization and finalizes with autonomous (technical) system.

Finally, a demand of compliance to extrinsic terms, the environment and of organizational redesign form new human role in disruptive digital transformation in economics and society.

Further elaboration of these points might be focused on shaping up a deep concept of organizational transformation on every stage of its evolution from digital technologies point of view and on defining every single role of organization's members who should be played on the way of efficient digital transformation at its every stage.

\section{References}

1. D. Provan, D. Woods, S. Dekker, A. Rae, Reliability Engineering \& System Safety, 195, 106740 (2020)

2. Acatech, https://en.acatech.de/publication/industrie-4-0-maturity-index-update-2020 (2020)

3. Merriam-Webster Unabridged Dictionary, https://www.merriamwebster.com/dictionary/bionic (2021)

4. DaytonDailyNews, http://www.daytondailynews.com (2009)

5. Digitaltrends.ru, https://digitaltrends.rt.ru/reports/multiple_sources_rating (2021)

6. McKinsey, https://www.mckinsey.com/featured-insights/future-of-work/the-future-ofwork-after-covid-19\# (2021)

7. Teqviser, https://teqviser.ru (2021)

8. C. Carr, Performance Improvement, 28(9), 44-46 (1989)

9. G. A. Cohen, J. S. Parkinson, Perspectives on Business Innovation 8, 79-84 (2002)

10. M. Everson, J. Sviokla, https://www.strategy-business.com/article/The-BionicCompany?gko=41603 (2018)

11. R. Hutchinson, L. Aré, J. Rose, A. Bailey, https://www.bcg.com/enru/publications/2019/bionic-company (2019)

12. S. Singh, A. El-Kassar, Journal of Cleaner Production, 213, 1264-1273 (2019)

13. W. Strielkowski, Social Impacts of Smart Grids: The Future of Smart Grids and Energy Market Design (2019)

14. R. Rawassizadeh, T. Sen, S.J. Kim, C. Meurisch, H. Keshavarz, M. Mühlhäuser, M. Pazzani, Transactions on Pervasive Computing and Interaction, 1, 163-174 (2019)

15. A. Trunk, H. Birkel, E. Hartmann, Business Research, 13, 875-919 (2020)

16. R.B. Bouncken, S. Kraus, J.F. Martínez-Pérez, International Entrepreneurship and Management Journal, 16, 1465-1481 (2020)

17. I.R.P. Cuypers, G. Ertug, J. Cantwell, A. Zaheer, M. Kilduff, Journal of International Business Studies, 51, 714-736 (2020)

18. R. Alt, J.M. Leimeister, T. Priemuth, S. Sachse, N. Urbach, N. Wunderlich, Business \& Information Systems Engineering, 62, 609-621 (2020)

19. BBC, https://www.bbc.com/russian/news-45984669 (2019)

20. B. Gavurova, R. Bacik, R. Fedorko, M. Rigelsky, Marketing and Management of Innovations, 2, 186-200 (2018) 